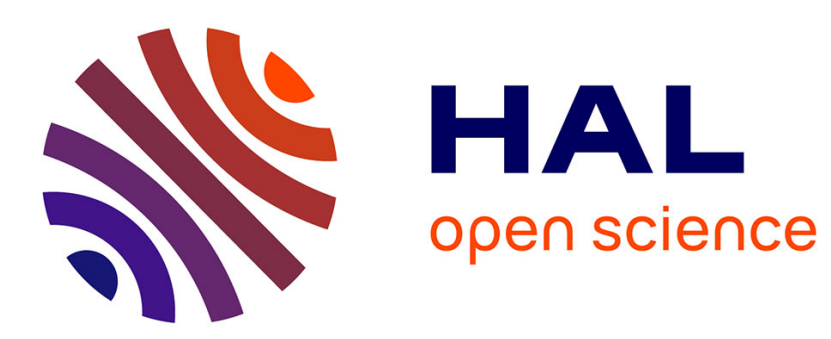

\title{
The role of internal stresses on the plastic deformation of the Al-Mg-Si-Cu alloy AA6111
}

Henry Proudhon, Warren J Poole, Xiang Wang, Yves Jm Brechet

\section{To cite this version:}

Henry Proudhon, Warren J Poole, Xiang Wang, Yves Jm Brechet. The role of internal stresses on the plastic deformation of the Al-Mg-Si-Cu alloy AA6111. Philosophical Magazine, 2008, 88 (05), pp.621-640. 10.1080/14786430801894569 . hal-00513861

\section{HAL Id: hal-00513861 \\ https://hal.science/hal-00513861}

Submitted on 1 Sep 2010

HAL is a multi-disciplinary open access archive for the deposit and dissemination of scientific research documents, whether they are published or not. The documents may come from teaching and research institutions in France or abroad, or from public or private research centers.
L'archive ouverte pluridisciplinaire HAL, est destinée au dépôt et à la diffusion de documents scientifiques de niveau recherche, publiés ou non, émanant des établissements d'enseignement et de recherche français ou étrangers, des laboratoires publics ou privés. 


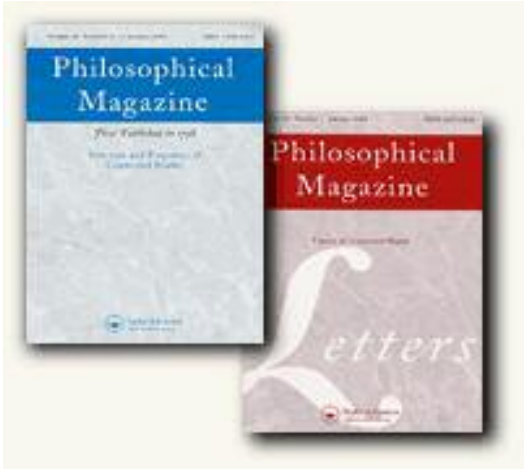

The role of internal stresses on the plastic deformation of the Al-Mg-Si-Cu alloy AA6111

\begin{tabular}{|r|l|}
\hline Journal: & Philosophical Magazine \& Philosophical Magazine Letters \\
\hline Mournal Selection: & Philosophical Magazine \\
\hline Author: & 19-Dec-2007 \\
\hline Complete List of Authors: & $\begin{array}{l}\text { Proudhon, Henry; Ecole des Mines de Paris, Centre des Materiaux, } \\
\text { UMR CNRS 7633 } \\
\text { Poole, Warren; The University of British Columbia, Dept. of } \\
\text { Materials Engineering } \\
\text { Wang, Xiang; McMaster University, Department of Materials Science } \\
\text { and Engineering } \\
\text { Brechet, Yves; LTPCM, INPG }\end{array}$ \\
\hline Keywords: & $\begin{array}{l}\text { precipitation, strengthening mechanisms, stress-strain } \\
\text { measurements, work-hardening }\end{array}$ \\
\hline $\begin{array}{l}\text { Keywords (user supplied): } \\
\text { Bauschinger stress }\end{array}$ \\
\hline $\begin{array}{l}\text { Note: The following files were submitted by the author for peer review, but cannot be converted } \\
\text { to PDF. You must view these files (e.g. movies) online. }\end{array}$ \\
\hline $\begin{array}{l}\text { bauschinger_aa6111.tex } \\
\text { bauschinger_aa6111.bbl } \\
\text { bibliography.bib }\end{array}$ \\
\hline
\end{tabular}

\section{ScholarONE" \\ Manuscript Central}


 \\ Page 1 of 34}

政事

\section{http://mc.manuscriptcentral.com/pm-pml}


Philosophical Magazine,

Vol. 00, No. 00, DD Month 200x, 1-26

\title{
The role of internal stresses on the plastic deformation of the $\mathrm{Al}-\mathrm{Mg}-\mathrm{Si}-\mathrm{Cu}$ alloy
}

\author{
AA6111 \\ H. Proudhon ${ }^{\dagger}$, W.J. Poole* ${ }^{* \dagger}$, X. Wang ${ }^{\ddagger}$, Y. Bréchet ${ }^{\S}$ \\ †Dept. of Materials Engineering, The University of British Columbia, \\ 309-6350 Stores Road, Vancouver BC V6T1Z4, Canada \\ ${ }^{\ddagger}$ Dept. of Material Science and Engineering, Master University, \\ 1280 Main St. West, Hamilton ON L8S4L7, Canada \\ ${ }^{\S}$ LTPCM, INP Grenoble, BP75, 38402 St. Martin d'Heres, France \\ (Received 00 Month 200x; in final form 00 Month 200x)
}

\begin{abstract}
In this work, we have investigated the internal stress contribution to the flow stress for a commercial 6xxx aluminium alloy (AA6111). In contrast to stresses from forest and precipitation hardening, the internal stress cannot be assessed properly with a uniaxial tensile test. Instead, tension-compression tests have been used to measure the Bauschinger stress and produce a comprehensive study which examines its evolution with i) the precipitation structure and ii) a wide range of applied strain. A large set of ageing conditions was investigated to explore the effect of the precipitation state on the development of internal stress within the material.

It is shown that the Bauschinger stress generally increases with the applied strain and critically depends on the precipitate average radius and is thus linked to the shearable/non shearable transition. Further work in the case of non-shearable particles shows that higher strain eventually lead to particle fracture and the Bauschinger stress then rapidly decreases. Following the seminal work of Brown et al, a physically based approach including plastic relaxation and particle fracture is developed to predict the evolution of the internal stress as a function of the applied strain. Knowing the precipitation structure main characteristics - such as the average precipitate radius, length and volume fraction- allows one to estimate accurately the internal stress contribution to the flow stress with this model.
\end{abstract}

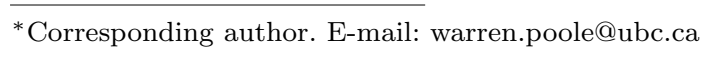

Philosophical Magazine

ISSN 1478-6435 print/ISSN 1478-6443 online (C) 200x Taylor \& Francis

http://www.tandf.co.uk/journals 


\section{December 19, 2007}

\section{Introduction}

A complete understanding of the plastic behaviour of two phase materials requires a multi-faceted approach as the presence of a second phase introduces a variety of new possible deformation mechanisms compared to single phase materials. At a general level, the second phase modifies the work hardening of material due to partitioning of stress and strain between the two phases. The modeling of these stresses for a wide range of volume fractions and particle shapes can be examined using by continuum models such as load transfer models, Eshelby and finite element method calculations [1,2]. Alternatively, dislocation based models can be considered. Using the concept of geometrically necessary dislocations, the seminal work of Ashby examined the work hardening of $\mathrm{Cu}-\mathrm{SiO}_{2}$ single crystals [3]. In this work, an intrinsic length scale, "the geometric slip distance", can be introduced to account for the effects of particle size, shape (plates vs. spheres) and volume fraction. In recent years, it has become possible to examine plasticity problems using discrete dislocation models; this seems to be promising in complex situations such as two phase systems e.g. see Cleveringa and Van Der Giessen [4], but much more work is needed here before commercially relevant systems can be explored.

Each approach has its limitations. For example, dislocation models have difficulty in predicting internal stresses such as observed during strain path changes (e.g. Bauschinger tests) while continuum models are inherently scale independent and cannot account for particle size effects. As a result, modelling approaches which incorporate aspects of both continuum and dislocation based approaches have been developed [5]. For example, Brown and Stobbs developed a comprehensive framework to describe the work hardening behaviour for the $\mathrm{Cu}-\mathrm{SiO}_{2}$ single crystals system [6,7]. Most recently, it has been shown that it is possible to extend continuum plasticity models by using higher order plasticity theories such as strain gradient plasticity which explicitly include a length scale [8].

It is also important to consider the possible interactions between plasticity and the second phase. First, for small particles (e.g. precipitates) which are sheared by dislocations, the increase in interfacial area can lead to the dissolution of the second phase $[9,10]$. Alternatively, deformation may lead to dynamic precipitation $[11,12]$. Second, the build of internal stresses can lead to the intervention of alternative 
processes such as particle fracture, interfacial decohesion or in the case of high aspect particles under compressive loading, elastic buckling and the formation of shear bands [13]. In general, these processes depend critically on the stress-state, e.g. the magnitude and direction of the hydrostatic and deviatoric stresses.

Precipitation hardening aluminum alloys represent a particularly interesting and challenging two-phase system to examine. During precipitation, the volume fraction, size, shape and the composition of the second phase changes (i.e. a series of metastable precipitates is often observed). The early work of Byrne and co-workers [14] on $\mathrm{Al}-\mathrm{Cu}$ single crystals found that there was a substantial change in macroscopic work hardening behaviour as a function of the precipitate state. A fundamental question that arose from these studies and the later work of Moan and Embury [15] was whether the enhanced work hardening behaviour observed in the $\mathrm{Al}-\mathrm{Cu}$ samples (which have plate shaped precipitates) was best understood in the framework of additional storage of geometrically necessary dislocations (Ashby) or in terms of the development of long range back stress $[6,16,17]$. It is not possible to differentiate these theories based on monotonic tests but the use of strain reversal, i.e. Bauschinger tests, is particularly useful for evaluating internal stresses $[15,18,19]$.

The current work examines the development of internal stresses as a function of precipitate state for the commercial aluminum alloy AA6111 using Bauschinger experiments. This system is a good candidate for detailed examination as it has recently been well characterized in terms of the nature of the precipitates, their size, shape and volume fraction [20-22] as well as the macroscopic work hardening behaviour [23] for a wide range of heat treatments. It is the objective of the current work to develop a comprehensive model framework for understanding the development of internal stresses in this alloy system for deformation at ambient temperature over a wide range of strains (i.e. strains from 0.01 to 0.6 ).

\section{Experimental Methods}

A commercial aluminium alloy AA6111, provided by Novelis Global Technology Centre (Kingston, ON) was used for this study. The material was obtained in form of a rolled sheet of $10 \mathrm{~mm}$ thickness and 
hical Magazine bauschinger aa 6111

H. Proudhon et al.

Table 1. Chemical composition of the AA6111 alloy (wt.\%)

\begin{tabular}{cccccccc}
\hline Alloy & $\mathrm{Mg}$ & $\mathrm{Si}$ & $\mathrm{Cu}$ & $\mathrm{Fe}$ & $\mathrm{Mn}$ & $\mathrm{Cr}$ & $\mathrm{Ti}$ \\
\hline AA6111 & 0.8 & 0.6 & 0.7 & 0.25 & 0.2 & 0.05 & 0.06 \\
\hline
\end{tabular}

Table 2. Details of the five heat treatments applied to the specimens

\begin{tabular}{lcccl}
\hline Condition & label & solutionizing & quench & ageing \\
\hline Under aged & $5 \mathrm{M} 180$ & 10 min at $560{ }^{\circ} \mathrm{C}$ & WQ & 5 minutes at $180{ }^{\circ} \mathrm{C}$ in oil bath \\
Peak aged & $7 \mathrm{H} 180$ & 10 min at $560{ }^{\circ} \mathrm{C}$ & WQ & 7 hours at $180{ }^{\circ} \mathrm{C}$ in oil bath \\
Over aged 1 & $60 \mathrm{D} 180$ & 10 min at $560{ }^{\circ} \mathrm{C}$ & WQ & 1 hour at $250{ }^{\circ} \mathrm{C}$ in oil bath, then 60 days at $180{ }^{\circ} \mathrm{C}$ in air furnace \\
Over aged 2 & $6 \mathrm{H} 250$ & 10 min at $560{ }^{\circ} \mathrm{C}$ & WQ & 6 hours at $250{ }^{\circ} \mathrm{C}$ in oil bath \\
Over aged 3 & $7 \mathrm{D} 250$ & 10 min at $560{ }^{\circ} \mathrm{C}$ & WQ & 1 hour at $250{ }^{\circ} \mathrm{C}$ in oil bath, then 7 days at $250{ }^{\circ} \mathrm{C}$ in air furnace \\
\hline
\end{tabular}

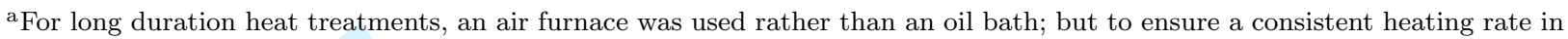
all experiments, the first hour was carried out in an oil bath like for the other treatments.

its chemical composition was determined as shown in Table 1. For the tension-compression tests, axisymmetrical specimens were machined in the sheet thickness with a $20 \mathrm{~mm}$ gage length and a diameter ratio of 1.63 (the diameter is $9 \mathrm{~mm}$ in the grip section v.s. $5.5 \mathrm{~mm}$ in the gage length section). Specimens were all solution treated for 10 minutes in a salt bath at $560{ }^{\circ} \mathrm{C}$. In order to study the effect of the precipitation structure, various ageing stages have been investigated. Based on previous work [24], 5 conditions have been selected from under-aged to massively over-aged, as shown in Table 2. For the sake of clarity, each condition will be hereafter identified by the combination of annealing time and temperature after quenching; e.g. $6 \mathrm{H} 250$ for 6 hours at $250^{\circ} \mathrm{C}$, see Table 2 for full details).

Mechanical tests were conducted on a computer controlled MTS servo-hydraulic machine. Tests have been conducted with a nominal strain rate of $10^{-3} \mathrm{~s}^{-1}$ at room temperature. One specimen for each condition was tested in tension to failure to record the tensile properties. Then for each ageing condition, tension-compression tests were conducted in the following way: during the first straining phase, the specimen was deformed under tension to a certain amount of plastic strain. A clip-on extensometer was used to monitor the total strain, the target value having been determined from the tensile test. The strain was then reversed to apply at least $6 \%$ plastic strain in compression and at this point the specimen is unloaded. Tests were conducted on different samples with four different amounts of plastic strain in the tension loading phase $(1 \%, 2 \%, 4 \%$ and $6 \%)$ to capture the evolution of the Bauschinger effect as a function of strain.

It will be shown that for the particular case of 7 days at $250{ }^{\circ} \mathrm{C}$, it is of interest to gather information on 
Table 3. Yield stress measured with $0.02 \%$ and $0.2 \%$ plastic strain offsets for all investigated materials.

\begin{tabular}{cccccc}
\hline Ageing & $5 \mathrm{M} 180$ & $7 \mathrm{H} 180$ & $60 \mathrm{D} 180$ & $6 \mathrm{H} 250$ & $7 \mathrm{D} 250$ \\
\hline$\sigma_{Y 0.02 \%}(\mathrm{MPa})$ & 110 & 310 & 285 & 210 & 140 \\
$\sigma_{Y 0.2 \%}(\mathrm{MPa})$ & 140 & 335 & 300 & 245 & 155 \\
\hline
\end{tabular}

the Bauschinger effect at larger strains (between $10 \%$ and $60 \%$ ). With the method described above, the strain is limited to moderate values due to either necking or buckling of the sample. Therefore, additional specimens were processed in the following way: four $50 \mathrm{~mm} \times 100 \mathrm{~mm} \times 10 \mathrm{~mm}$ plates of the as received sheet were cut and prepared with the 7D250 condition. Three of these samples were rolled to 10, 20 and $40 \%$ reduction (the fourth sample was not rolled and was used to ensure there was no variation in the heat treatment due to the bulky geometry of the plate compared to the dogbone specimens). Specimens were then machined from the four plates, and both tension and compression tests were conducted as previously described.

The samples for transmission electron microscopy (TEM) were prepared as follows: mechanical polishing down to approximately $100 \mu \mathrm{m}$ thickness and then jet polishing in a solution of $10 \%$ perchloric acid and $90 \%$ methanol at $-35^{\circ} \mathrm{C}$. TEM observations were conducted using a PHILIPS CM12 transmission microscope operating at $120 \mathrm{kV}$.

\section{Results}

As shown by Poole and co-workers in the same alloy, the yield and work hardening behaviour depends critically on the heat treatment history of the material [24]. From the tensile behaviour, the yield stress values corresponding to $0.2 \%$ and $0.02 \%$ of permanent deformation $\sigma_{0.2 \%}$ and $\sigma_{0.02 \%}$ respectively, were determined and reported in Table 3. Tensile curves for a large set of ageing conditions in this material can be found elsewhere [25].

Fig. 1 illustrates how the data recorded during the tensile testing was analysed. The process has three steps: (i) the true stress v.s. true strain curve is plotted; (ii) the compressive data is reversed and plotted as a function of cumulative strain; (iii) the elastic strain is removed and the true stress v.s. cumulative true strain can be compared to the monotonic behaviour. 
(a)

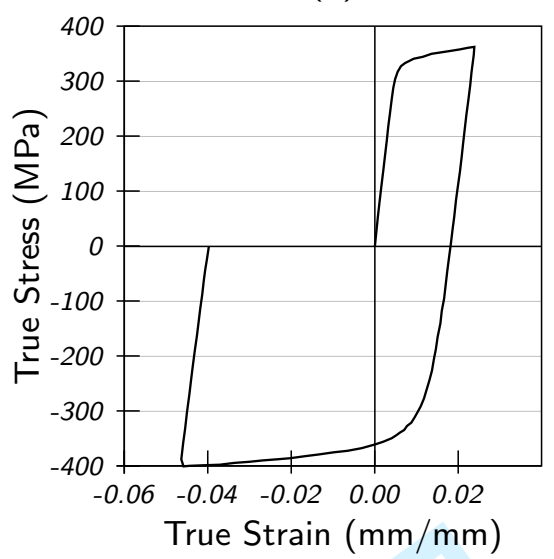

(b)

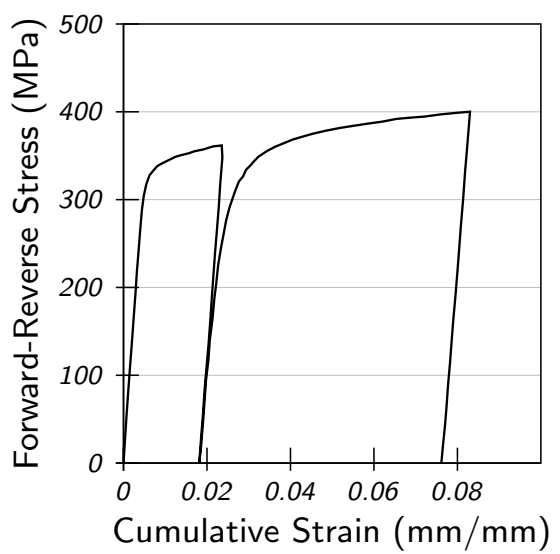

(c)

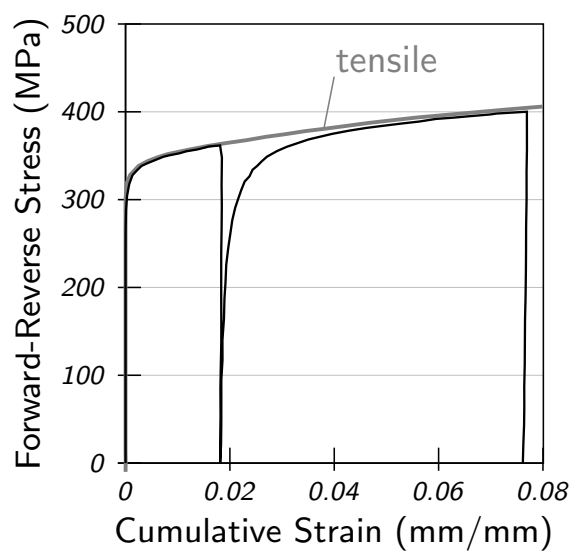

Figure 1. Illustration of the stress-strain data processing in a three steps way in the case of $7 \mathrm{H} 180$ material with $2 \%$ forward strain: (a) true stress v.s. true strain curve; (b) reversed stress data plotted v.s. cumulative true strain (c) the elastic strain is removed and the curve is compared with the monotonic behavior.

Fig. 2 shows the forward-reverse behaviour obtained for different heat treatments after $1 \%$ plastic strain applied in the forward direction. Similar data have been obtained for forward strain values of $2 \%, 4 \%$ and $6 \%$. One can readily observe that the reverse parts of the curves can be split in two; first a transient region where there is a very steep apparent work hardening rate, followed by a steady state one. The materials with different heat treatments show very different behaviours. For the under aged and peak aged material, the transient is rather short and the flow stress quickly comes back to the value reached during the forward straining. On the other hand for the over aged materials, the transient progressively becomes longer and more complicated. In particular for the materials aged at $250{ }^{\circ} \mathrm{C}$, the transient part seems much more complicated with an inflexion in the reverse flow stress curve. While an in-depth investigation of the microscopic processes responsible of this inflexion is beyond the scope of this paper, it should be noted that this behaviour has been reported before $[26,27]$ and was attributed to the recovery of the dislocation structures formed during the forward straining.

\subsection{Bauschinger stress analysis}

As previously suggested by Wilson [18] and followed by Atkinson et al. [16], the evolution of the Bauschinger stress $\sigma_{b}$ as a function of the reverse plastic strain can be calculated by halving the difference between the monotonous and the reversed stress-strain data. The corresponding curves are shown in Fig. 3. This representation is useful to compare between different materials and can give important information on the 

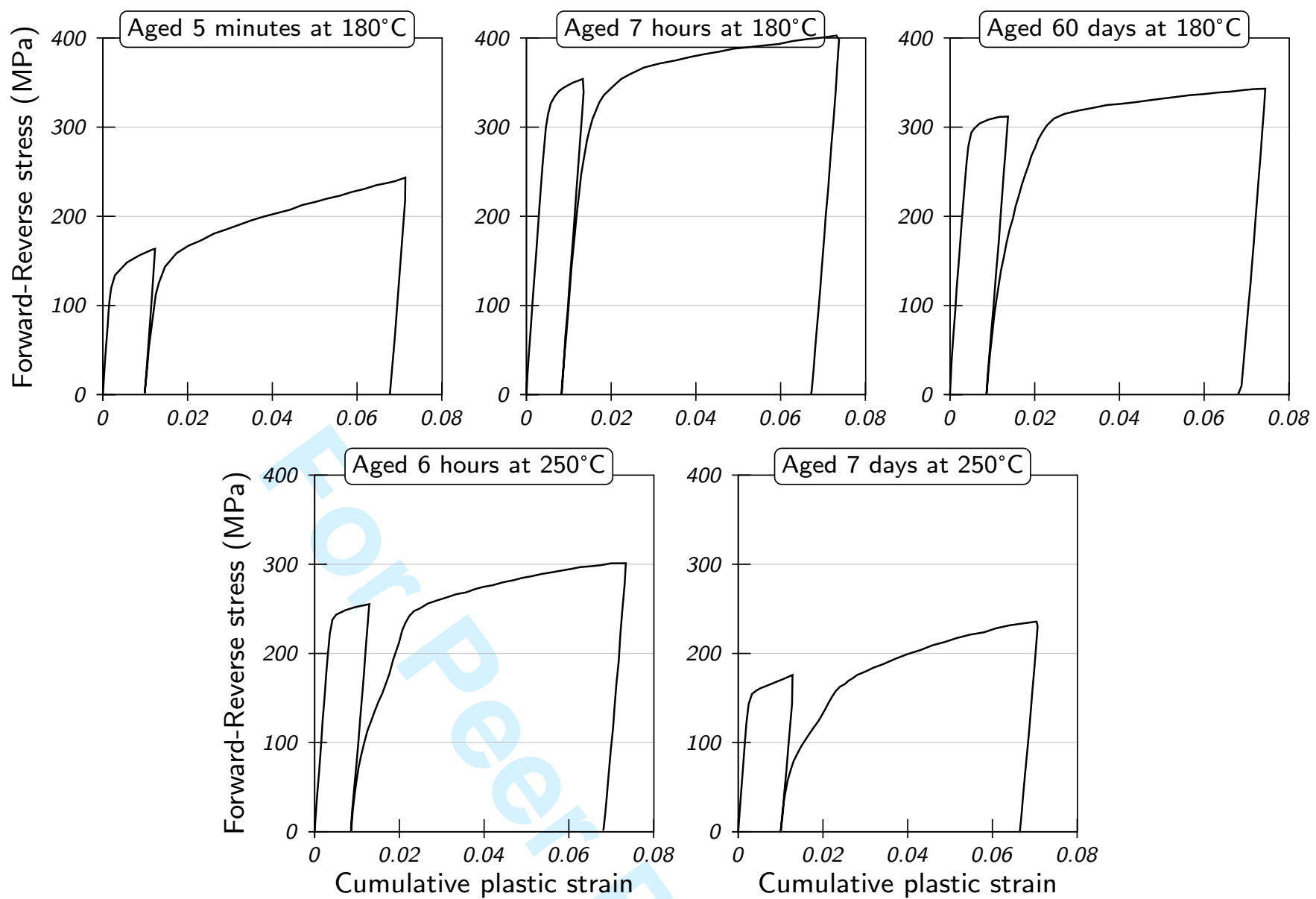

Figure 2. Forward-reverse stress/strain curves, obtained by a Bauschinger test with a $1 \%$ forward plastic strain, for all materials.

evolution of the internal structure as the reverse strain develops. Fig. 3 presents a summary of the results of all Bauschinger tests. One can see that the results obtained for the $1 \%$ forward strain (see Fig. 2) are similar for the other values of $2 \%, 4 \%$ and $6 \%$; however it is clear that for a given material, the general value of the Bauschinger stress increases as a function of the forward strain.

The difference in terms of the evolution of the Bauschinger stress as the reverse strain increases is significant. On the one hand, the under aged and peak aged materials (and to a lesser extend for the 60D180 material which appears to be an intermediate case), undergo a short transient stage (approximately $1 \%$ plastic strain) where the Bauschinger stress decreases very rapidly. After this transient decrease, the Bauschinger stress, if any, decreases to a low value. On the other hand, the over aged materials $6 \mathrm{H} 250$ and 7D250 show a more complicated behaviour with higher values of Bauschinger stress. The transient is still observed (approximately 1\% plastic strain) followed by a regime where the Bauschinger stress decreases in a linear manner with increasing plastic strain. 

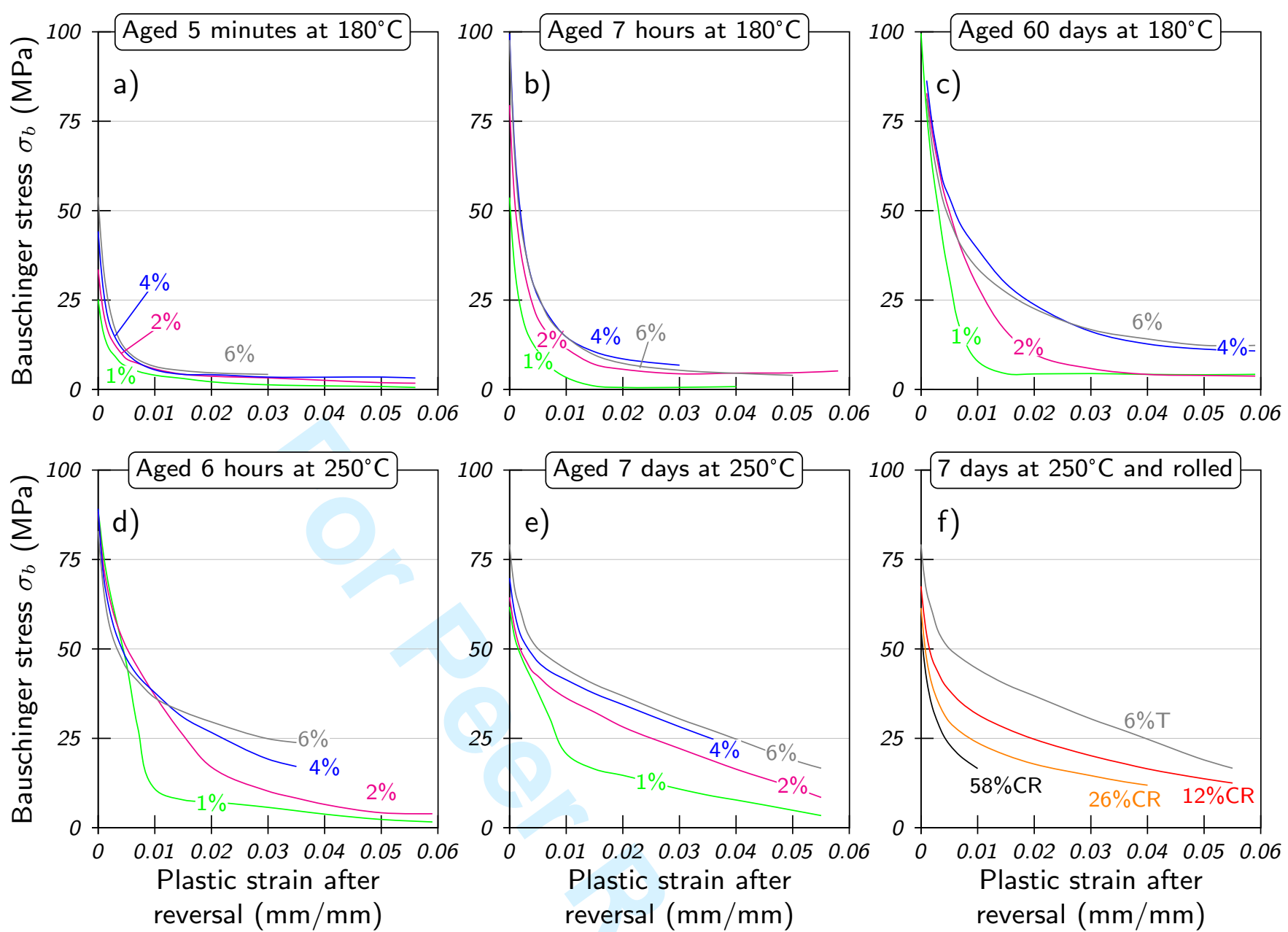

Figure 3. Bauschinger stress as a function of reverse plastic strain. For each ageing condition, 4 different forward strains were tested $(1 \%, 2 \%, 4 \%$ and $6 \%)$; the curves for rolled samples are shown in the bottom right graph and have been annoted "CR".

To further analyse these data, it is useful to choose a plastic strain offset to characterise the Bauschinger stress $\sigma_{b}$. This is a rather important issue as the choice of the offset significantly affects the results. Examination of the literature shows that there is no general agreement on this choice. In the work of Brown and coworkers on copper-silica, the internal stress is defined as being "permanent softening" and thus measured when the reverse curve becomes parallel to the tensile behaviour. This method does not seem suitable in our case since permanent softening is not readily observed. Alternatively, Lloyd chose to use a $3 \%$ plastic strain offset [28], while Moan and Embury focused on the transient behavior and have used very small offset values — between $0.001 \%$ and $0.1 \%$ plastic strain - to characterize the Bauschinger effect [15].

Table 4 presents the results showing the effect of choosing different reverse strains, i.e. $0.5,1$ and $2 \%$, to estimate the Bauschinger stress from the experimental results. For the cases of 5M180 and 7H180, the 
Table 4. Measure of the Bauschinger stress (MPa) in the tensioncompression tests presented on Fig. 3 with three different plastic strain offsets.

\begin{tabular}{cccccc}
\hline Forward strain & $5 \mathrm{M} 180$ & $7 \mathrm{H} 180$ & $60 \mathrm{D} 180$ & $6 \mathrm{H} 250$ & $7 \mathrm{D} 250$ \\
\hline \multicolumn{7}{c}{ plastic } & strain offset $=0.5 \%$ \\
\hline $1 \%$ & 6.5 & 10.7 & 31.3 & 45.8 & 37.9 \\
$2 \%$ & 8.6 & 19.8 & 49.8 & 50.3 & 42.4 \\
$4 \%$ & 10.1 & 26.0 & 53.7 & 47.3 & 46.4 \\
$6 \%$ & 11.0 & 26.5 & 47.7 & 44.6 & 50.6 \\
\hline \multicolumn{7}{c}{ plastic } & strain offset =1\% & & \\
\hline $1 \%$ & 4.0 & 3.4 & 7.9 & 10.8 & 20.7 \\
$2 \%$ & 5.8 & 11.5 & 28.9 & 37.0 & 36.3 \\
$4 \%$ & 5.5 & 14.7 & 39.3 & 37.8 & 41.4 \\
$6 \%$ & 6.4 & 14.7 & 33.8 & 36.3 & 45.4 \\
\hline \multicolumn{7}{c}{ plastic } & strain offset $=2 \%$ & & \\
\hline $1 \%$ & 2.1 & 1.0 & 4.4 & 7.3 & 14.7 \\
$2 \%$ & 5.1 & 5.7 & 9.9 & 16.9 & 28.2 \\
$4 \%$ & 4.2 & 6.1 & 23.7 & 26.6 & 34.9 \\
$6 \%$ & 4.2 & 7.3 & 22.6 & 29.6 & 36.9 \\
\hline
\end{tabular}

choice of reverse strains has almost no practical effect, i.e. in all case the estimated stress is small, ranging from $1-8 \%$ of the yield stress. The value of $8 \%$ will be taken as a worst case estimate for the resolution of this technique. On the other hand, in the case of $6 \mathrm{H} 250$ or 7D250 the effect of the choice for reverse strains is more important, especially for low forward strains. By far the biggest difference in the estimate occurs when the reverse strain is increased from 0.5 to $1 \%$. This is consistent with the data plotted in Fig. $3 \mathrm{~d}$ and 3e which shows that the estimate of Bauschinger stress is changing rapidly in this range of the reverse strain. After 1\% reverse strain the rate of change of Bauschinger stress is much lower in all cases.

It is well known that during the initial stage of the strain reversal, the dislocation structure is evolving in a complicated manner. For example, even single phase materials such as copper exhibit significant transient effects [29]. Considering the strain resulting from the local motion of a dislocation sampling an array of point obstacles when the strain is reversed, Brown estimated that the transient strain would be approximately $1 \%$ plastic strain [19]. This would be consistent with the present results which show that the region where the reverse stress is evolving the most rapidly also corresponds to approximately $1 \%$ plastic strain. As a result, the subsequent discussion will use the results obtained at $1 \%$ plastic reverse strain $\sigma_{r 1 \%}$, as an estimate of the internal stress, see Eq. (1). While this is not completely satisfying from a theoretical point of view, we feel that in the absence of direct measurements for the stress in the second phase (by for example in situ X-ray diffraction), this represents a reasonable approach. 
The Bauschinger stress, measured with a $1 \%$ plastic strain offset $\sigma_{b 1 \%}$, is thus used to estimate the value of the internal stress $\langle\sigma\rangle$ stored within the material at the point of reversal (where $\sigma_{f_{0}}$ denotes the flow stress reached at this point). From now on we shall use the term internal stress regardless whether we are refering to the experimental Bauschinger results or to the stress actually stored within the material. Hence:

$$
\langle\sigma\rangle=\sigma_{b 1 \%}=\frac{\sigma_{f_{0}}-\left|\sigma_{r 1 \%}\right|}{2}
$$

The measured internal stress increases in all cases with plastic strain as shown in Fig. 4a; but clearly, the five studied materials break into two groups. The under aged and peak aged materials show very little internal stress and the over aged materials show a significant level. The internal stress $\langle\sigma\rangle$ first increases with a very steep slope and then remains more or less stable, as shown by the upper dashed line on the figure.

Having characterised the internal stress, it is interesting to be able to estimate the fraction of the work hardening which can be attributed to the internal stress. This can be done by plotting the ratio of the internal stress to the level of work hardening: $\langle\sigma\rangle /\left(\sigma_{f_{0}}-\sigma_{Y 0.02 \%}\right)$ as shown in Fig. 4b. Again the five materials separate into two groups, underaged and peak aged materials have less than $20 \%$ of the work hardening which can be attributed to internal stress build-up while for the overaged materials, more than $50 \%$ of the work hardening (up to $86 \%$ for 7 D250) can be attributed to the evolution of internal stress.

\subsection{Large strain experiments with material aged 7D250}

As shown by the results in Fig. 4, the material aged 7D250 exhibits a very large internal stress when it is plastically deformed. It is clear that the internal stress increases with the applied forward plastic strain but it is of interest to see if there is a limit to this increase. This cannot be answered from these experiments because we were limited to approximately $7-8 \%$ plastic strain due to either necking or buckling. Much 

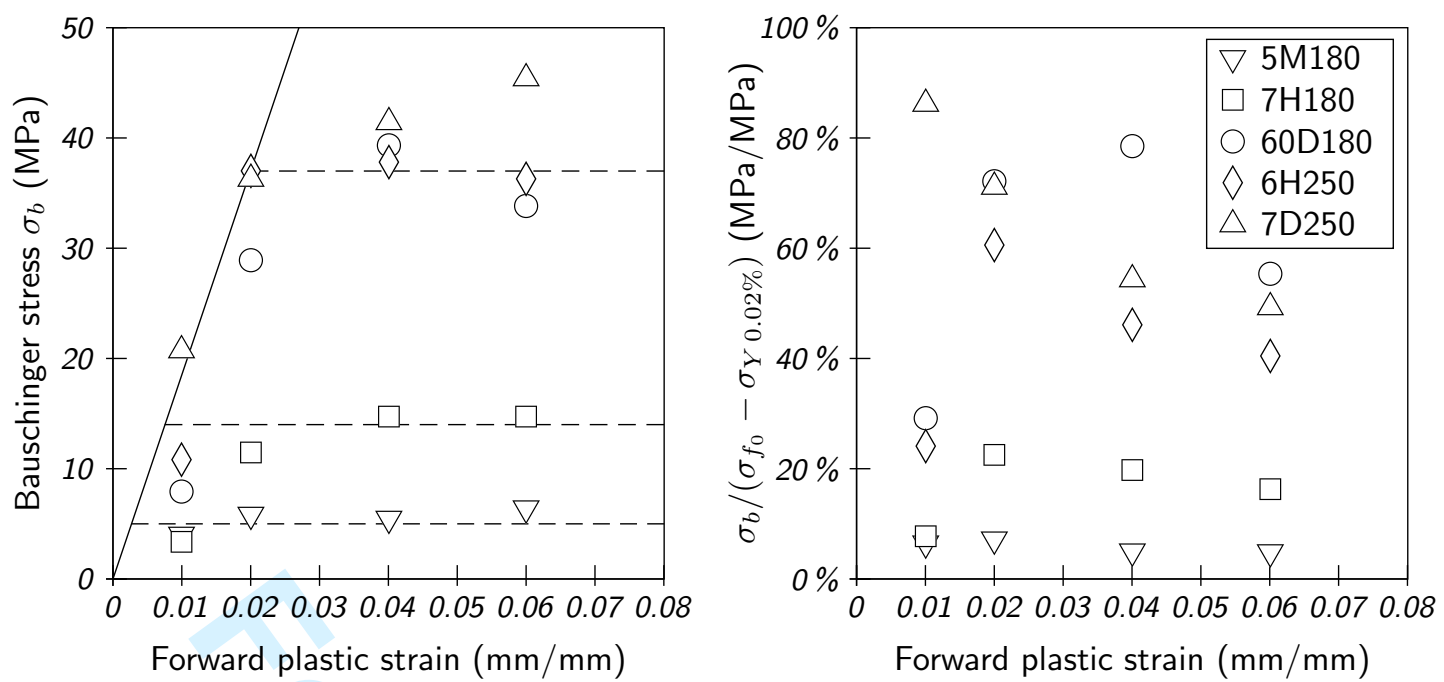

Figure 4. Internal stress measurements in AA6111, a) $\langle\sigma\rangle$ measured after $1 \%$ reverse strain, b) $\langle\sigma\rangle$ expressed as a percentage of the work hardening of the materials; symbols denote the same materials in both pictures.

\begin{tabular}{|c|c|}
\hline Plastic strain (\%) & Bauschinger stress $\sigma_{b}(\mathrm{MPa})$ \\
\hline 1 & 20.7 \\
\hline 2 & 36.3 \\
\hline 4 & 41.4 \\
\hline 6 & 45.4 \\
\hline 12 & 31.7 \\
\hline 25.6 & 23.8 \\
\hline 58.7 & 16.6 \\
\hline
\end{tabular}

higher values of strain can be achieved by cold rolling the material ${ }^{1}$. Considering the von Mises equivalent stress, rolling to $10 \%, 20 \%$ and $40 \%$ reduction lead to forward strain values of $0.12,0.26$ and 0.58 . The experimental results for the Bauschinger stress as a function of reverse strain are presented in Fig. $3 \mathrm{f}$ and the corresponding results in terms of internal stress measured after $1 \%$ reverse plastic strain are summarized in Table 5 together with the other values measured with the tension-compression tests for 7D250.

It is clear that the increase of the internal stress observed before $10 \%$ strain does not continue. In fact, it is observed that after $10 \%$ plastic strain, the internal stress start decreasing. Fig. 5 presents some TEM micrographs of 7D250 material which provides evidence as to what is happening. Fig. 5a is a dark field image of a sample deformed $8 \%$ in tension. The dislocation structure is complex but one should observe that the precipitates are still intact and very straight. Fig. 5b and Fig. 5c are bright field images of cold

\footnotetext{
${ }^{1}$ Note: to a first approximation, one does not expect a large difference in the internal structure for specimens submitted to rolling $v s$. tensile deformation
} 


\section{Page 13 of 34}

hical Magazine bauschinger aa6111

Philosophical Magazine \& Philosophical Magazine Letters

H. Proudhon et al.

(a)

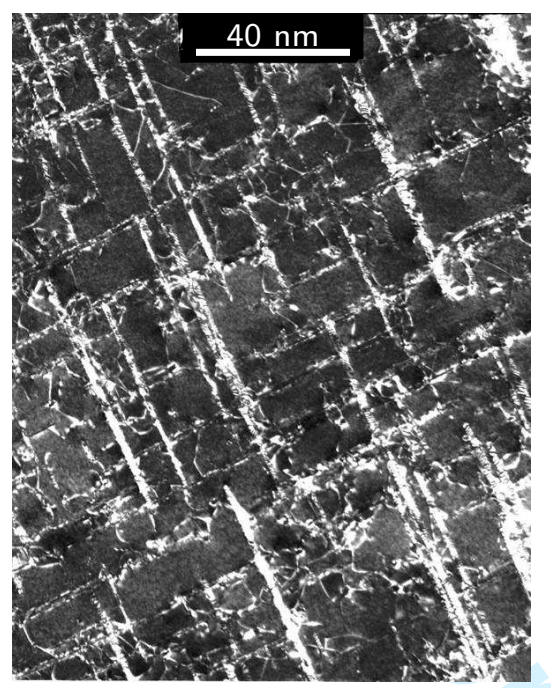

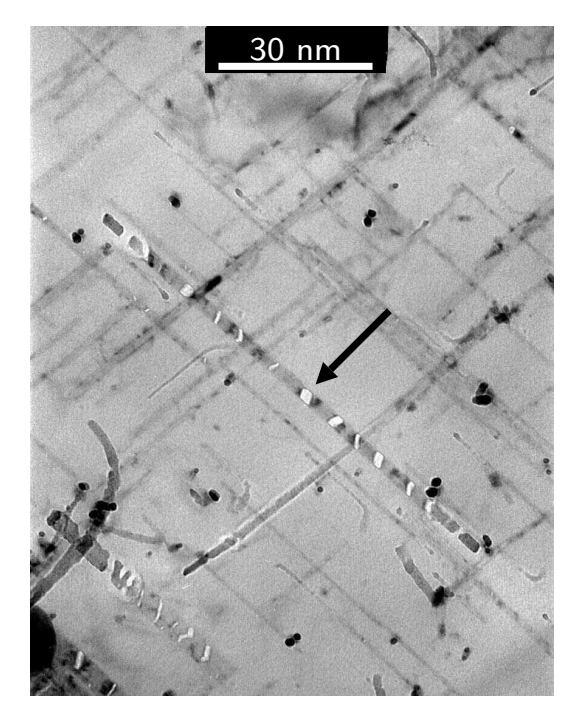

(b) (c)

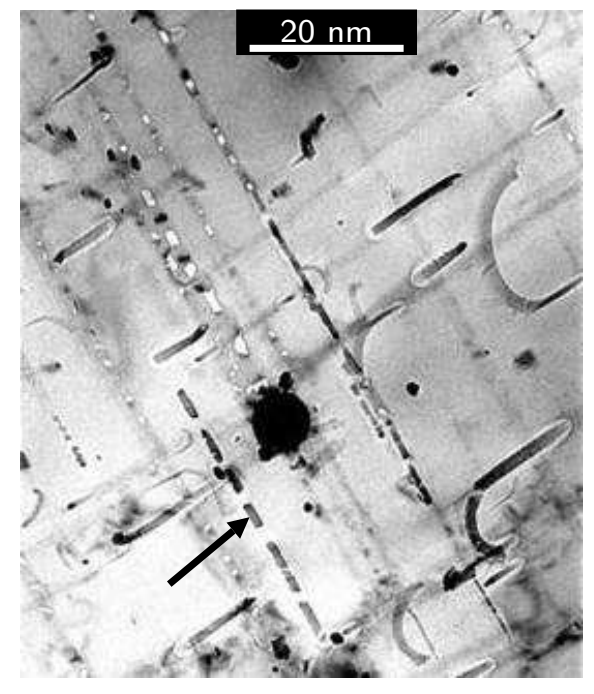

Figure 5. Observation of the microstructure of material 7D250 by TEM: a) dark field image of a sample deformed $8 \%$ in tension, b) bright field image after $20 \%$ cold rolling, c) bright field image after $40 \%$ cold rolling; arrows indicate examples of precipitates fracture.

rolled specimens for $20 \%$ and $40 \%$ reduction. One should note in the latter two cases that the precipitates have fractured; this has actually been observed also for the $10 \%$ reduction cold rolled specimens.

\section{Discussion}

The results presented in the previous section have shown that depending on the thermal history of the material, very different behaviours are observed in terms of internal stress build-up. This section deals with analysing the results regarding the interaction of the dislocations with the precipitation structure. First we review the importance of the shearable/non-shearable transition and then the intervention of alternative processes is considered for the case of non-shearable particles.

\subsection{The shearable/non-shearable transition}

There is a general agreement about the precipitation sequence of strengthening alloys such as AA6111.

That sequence can be written as follow:

$$
\mathrm{SSS} \rightarrow \text { clusters/GP zones } \rightarrow \beta^{\prime \prime} \text { precursor of } Q \rightarrow \text { equilibrium } Q+\mathrm{Mg}_{2} \mathrm{Si}
$$

Here, SSS denotes the supersaturated solid solution; $\beta^{\prime \prime}$ are $\mathrm{Mg}_{5} \mathrm{Si}_{6}$ needle shaped precipitates lying in the $\langle 100\rangle$ direction of the aluminium matrix; $Q$ are lath shaped precipitates whose chemical composition 
Table 6. Summary of the main information describing the precipitates structure in the 5 studied materials.

\begin{tabular}{lccl}
\hline material & nature of precipitates & average radius & precipitates are... \\
\hline $5 \mathrm{M} 180$ & $\beta^{\prime \prime}+Q^{\prime}$ & $<1.2 \mathrm{~nm}$ & shearable \\
7H180 & $\beta^{\prime \prime}+Q^{\prime}$ & $1.8 \mathrm{~nm}$ & shearable \\
60D180 & $Q$ & $3.3 \mathrm{~nm}$ & mixed \\
6H250 & $Q$ & $\sim 5 \mathrm{~nm}$ & mixed, mostly non-shearable \\
7D250 & $Q$ & $6.6 \mathrm{~nm}$ & non-shearable \\
\hline
\end{tabular}

is likely to be $\mathrm{Al}_{4} \mathrm{Cu}_{2} \mathrm{Mg}_{8} \mathrm{Si}_{7}$; and $\mathrm{Mg}_{2} \mathrm{Si}$ is a plate shaped equilibrium phase (for full details with TEM observations and references on the precipitation sequence, see [20]).

Table 6 provides a summary of the precipitates structure and the nature of the dislocations/precipitates interaction (based on monotonic work hardening and TEM studies) for the 5 different materials examined in this work. According to Table 6, one can correlate the observed behaviour for the internal stress build up during deformation with the nature of the dislocations/precipitates interactions. When the dislocations can pass through the precipitates (5M180 and $7 \mathrm{H} 180$ ), no Orowan loop is left around the precipitates and little or no internal stress is found within the material. As the size of precipitates increases, at some point it will become impossible for the dislocation to pass through. At this point, the dislocation will bow between the precipitates and then by-pass the precipitates, leaving one dislocation loop around the particle for each mobile dislocation. This mechanism is responsible for the internal stress measured in the cases of materials $6 \mathrm{H} 250$ and 7D250. In the case of 60D180, it is believed that the distribution is mixed — see [24] for high resolution TEM evidence that some precipitates are still sheared by the dislocations - so both mechanisms coexist which is consistent with the intermediate value of internal stress that was observed.

\subsection{Deformation mechanisms at larger strains}

The mechanical tests carried out on the rolled 7D250 samples have shown that the internal stress first increases with forward strain and then after approximately $10 \%$, starts to decrease as a function of the amount of reduction. In other words, increasing the deformation in the specimen actually reduces the internal stress stored inside the material.

At first sight, this behavior seems inconsistent with the mechanisms we have just described, where the Bauschinger stress increases with $\varepsilon_{p}$. But this can be understood by the fact that the storage of more and 
more loops around the particle correspondingly increases the axial stress on it. Thus, it is reasonable that at some point, the number of loops around the particle is large enough that the particle will fracture. This hypothesis is supported by TEM observation of 7D250 deformed by rolling shown previously on Fig. 5 where the fracture of the precipitates can readily be observed.

\subsection{Experimental determination of the unrelaxed plastic strain}

It is of interest to extend furter the analysis of the Bauschinger stress data. For this, only the over aged materials will be considered since they are the only ones to contain a population of non-shearable particles. It has been shown for those materials that the internal stress first increases linearly (see Fig. 4a) with a slope $\Theta=d\langle\sigma\rangle / d \varepsilon$. Although more data points would be needed to measure these slopes precisely, one can estimate $( \pm 200 \mathrm{MPa})$ the following values: $\Theta_{60 \mathrm{D} 180}=1800 \mathrm{MPa}, \Theta_{6 \mathrm{H} 250}=2200 \mathrm{MPa}, \Theta_{7 \mathrm{D} 250}=2400$ MPa (this would be consistent with a slight increase in the volume fraction of precipitates as a function of ageing time).

Those experimental values can now be used to calculate the unrelaxed plastic strain $\varepsilon_{p}^{*}$ at the end of the forward loading for each experimental test. Because in the linear region (i.e. $\varepsilon_{p} \leq 2 \%$ ) the work hardening process is predominantly associated with storing more and more dislocation loops around the precipitates, the unrelaxed plastic strain is equal to the plastic strain:

$$
\varepsilon_{p}^{*}=\varepsilon_{p} \quad \text { for } \varepsilon_{p} \leq 2 \%
$$

and one can now calculate the unrelaxed plastic strain $\varepsilon_{p}^{*}$ for the data in Fig. 4a as:

$$
\varepsilon_{p}^{*}=\frac{\langle\sigma\rangle}{\Theta}
$$


The experimental values will be shown later on (see Fig. 6), together with the predictions achieved by the equation developed in section 5.1.

\section{$5 \quad$ Modeling}

\subsection{A constitutive equation for the unrelaxed plastic strain, $\varepsilon_{p}^{*}$}

Brown and coworkers derived an expression for the internal stress starting with the unrelaxed shear plastic strain $\gamma_{p}^{*}[7]$. For spherical particles of radius $r, \gamma_{p}^{*}=n b / 2 r$ where $n$ is the number of dislocations responsible for the deformation, and $b$ represents the magnitude of their Burgers' vector. We shall consider a similar approach, while taking into consideration the particular geometry and size of the precipitates. In this case, the precipitates are lath shaped, aligned along the $\langle 100\rangle$ directions and the dislocation glide along slip planes $(\{111\}$ in FCC). Thus the precipitate length intercepting the slip planes $l \cos \theta$ replaces the sphere diameter $2 r$ in the previous expression, with $\theta=54.74^{\circ}$ :

$$
\gamma_{p}^{*}=\frac{n b}{l \cos \theta}
$$

The actual deformation in the direction of interest must be related to the effective Burgers' vector in that direction: $b \sin \theta$. Introducing the Taylor factor $M$ for multi-slip systems $(\gamma=M \varepsilon)$ leads to the following expression:

$$
\varepsilon_{p}^{*}=\frac{n b \sin \theta}{M l \cos \theta}
$$

Now the rate of creation of these dislocation loops $\mathrm{d} n / \mathrm{d} \gamma$, as the shear strain $\gamma$ operates, must be assessed. Because the loops will be stored along the axial direction of the precipitates, it should be proportional to $l \cos \theta /(b \sin \theta)$, the number of slip planes intercepting the precipitate. However, this dislocation 
accumulation around a precipitate cannot increase without limit. Either the internal stress will be suficient to fracture the particles and provide new free surfaces where the loops can annihilate, or the stresses at the interface will trigger recovery mechanisms preventing further accumulation. The net effect is that the number of loops that can be stored must have an upper limit $n^{*}$. That can be described easily if one pictures this effect as the maximum number of "available sites" $n^{*}$. If $n$ dislocations are stored, the proportion of sites unoccupied on which further storage is possible is $\left(1-n / n^{*}\right)$. Accounting of this effect amounts to multiply the "geometric storage rate" by this factor as expressed in Eq. (6). A similar approach as been recently used successfully to describe the storage of dislocations at grain boundaries [30]. Finally, one can write the rate of Orowan loops formation as:

$$
\frac{\mathrm{d} n}{\mathrm{~d} \gamma}=\frac{l \cos \theta}{b \sin \theta}\left(1-\frac{n}{n^{*}}\right)
$$

Using the Taylor factor and reordering give:

$$
\frac{\mathrm{d}\left(n / n^{*}\right)}{1-n / n^{*}}=\frac{M l \cos \theta}{n^{*} b \sin \theta} \mathrm{d} \varepsilon
$$

Integration of Eq. (7) leads to:

$$
\ln \left(1-\frac{n}{n^{*}}\right)=-\frac{M l \cos \theta \varepsilon}{n^{*} b \sin \theta}
$$

Then $n$ can be written: 


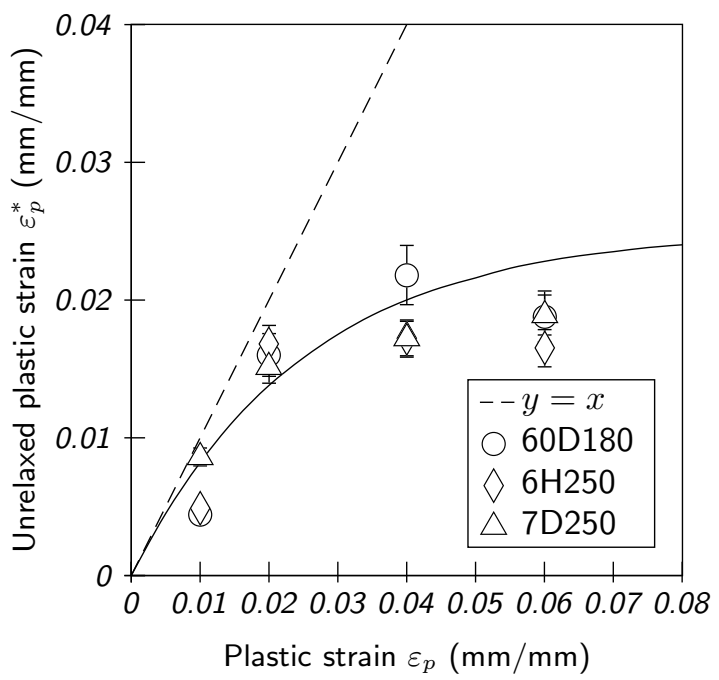

Figure 6. Prediction of the unrelaxed plastic strain by Eq. (9) (with $n^{*}=60$ ) compared to the values issued from the experiments and calculated with Eq. (3); as before, the error bars are based on a $200 \mathrm{MPa}$ uncertainty in the measure of $\Theta$.

$$
n=n^{*}\left(1-\exp \left(-\frac{M l \cos \theta \varepsilon}{n^{*} b \sin \theta}\right)\right)
$$

and finally, combining with Eq. (5), the unrelaxed plastic strain comes to:

$$
\varepsilon_{p}^{*}=\frac{n^{*} b \sin \theta}{l \cos \theta}\left(1-\exp \left(-\frac{M l \cos \theta \varepsilon}{n^{*} b \sin \theta}\right)\right)
$$

From a physical point of view, $n^{*}$ is the maximum number of dislocation loops which can be stored around the precipitate. One should note that, if $\varepsilon \rightarrow 0$, we have $\varepsilon_{p}^{*} \rightarrow \varepsilon_{p}$; which is consistent with the experiments as presented in $\S 4.3$ (this behaviour is observed for $\varepsilon_{p} \leq 2 \%$ ). The predictions for the unrelaxed plastic strain are presented together with the experimental values in Fig. 6.

\subsection{Modeling the internal stress}

In order to model the internal stress, we will use a combined continuum/dislocation based approach. As shown in Fig. 5, the precipitates can be considered as fibres oriented along the $\langle 100\rangle$ directions in an aluminum matrix (note the precipitates are lath shaped but we shall consider a simpler view where 
their cross section is represented by a circle with an equivalent radius $r_{0}=6.6 \mathrm{~nm}$ ). The average initial precipitate length $l_{0}$ is approximately $300 \mathrm{~nm}$, although there is some uncertainty here as it is difficult to measure in the TEM.

The internal stress $\langle\sigma\rangle$ is associated with the dislocations stored around the precipitates. According to this view, one can write:

$$
\langle\sigma\rangle=\alpha f \overline{\sigma_{p p t}}
$$

$f$ being the volume fraction of the precipitates, $\overline{\sigma_{p p t}}$ the average stress in the precipitates, and $\alpha$ a geometrical factor relative to the orientation of the precipitates with respect to the tensile axis. Because the experimental results have shown that it is important to account for the particle fracture, we shall adopt two different views depending wether or not the precipitate has been fractured or not:

- For unfractured precipitates, we use Eshelby's solution for ellipsoidal particles of high aspect ratio, i.e. the stress is uniform within the inclusion. Then we have $\overline{\sigma_{p p t}}=\sigma_{p p t}=E \varepsilon_{p}^{*}$, where $E$ is the modulus of elasticity of the precipitates in the deformation direction. While we can now estimate $\varepsilon_{p}^{*}$ from Eq. (9), determining the stiffness of the precipitates requires special attention and will be addressed in paragraph section 5.2.1.

- For fractured precipitates, we consider that the fracture process creates new free surfaces at the precipitates ends where the stress must now be zero. We then take the simplest possible view that the stress in the particles increases linearly from the end to the centre using a simple shear lag model which is presented in section 5.2.2.

5.2.1 the elastic constants of the $Q$ phase. The $Q$ phase precipitates are lath shaped, perfect HCP crystals of $\mathrm{Al}_{4} \mathrm{Cu}_{2} \mathrm{Mg}_{8} \mathrm{Si}_{7}$, aligned along the $\langle 100\rangle$ direction of the $\mathrm{Al}$ matrix. A critical piece of information needed is the elastic modulus of the crystal along its $c$ axis. Unfortunately, no experimental values are known. As a result, we will use the first-principles calculation by Wang and Wolverton [31]. The calculation 
Table 7. Elastic constants (unit is GPa) obtained by first-principles calculations for $\mathrm{Al}_{3} \mathrm{Cu}_{2} \mathrm{Mg}_{9} \mathrm{Si}_{7}$.

\begin{tabular}{cccccc}
\hline$C_{11}=C_{22}$ & $C_{12}$ & $C_{13}$ & $C_{33}$ & $C_{44}=C_{55}$ & $C_{66}=\left(C_{11}-C_{12}\right) / 2$ \\
\hline 147.3 & 36.8 & 31.0 & 128.3 & 36.4 & 55.5 \\
\hline
\end{tabular}

is made using the Vienna ab initio simulation package (VASP) with Vanderbilt ultrasoft pseudopotentials and the generalized gradient approximation (GGA). The stress-strain approach is employed with the 0K lowest energy DFT (density functional theory) stoichiometry $\mathrm{Al}_{3} \mathrm{Cu}_{2} \mathrm{Mg}_{9} \mathrm{Si}_{7}$ to give the elastic constants listed in Table 7.

Now, using the relations for hexagonal crystals (see for instance [32]), one can derive the stiffness coefficient $S_{i j}$ from the elastic constants. In particular, this leads to $S_{33}=0.00848 \mathrm{GPa}^{-1}$. Then the Young modulus can be derived:

$$
E=\frac{1}{S_{33}}=118 \mathrm{GPa}
$$

5.2.2 A simple plastic shear lag model for fractured precipitates. The Q phase precipitates are essentially perfect crystals, and as such will fail when the theoretical tensile strength $\sigma_{u}$, is reached. We shall consider that the particles are brittle, so once the load reaches $\sigma_{u}$, the particle fractures into two pieces of equal length. The experimental results suggest that the fracture stress of the precipitates should be within a 2500-3000 MPa range which is approximately $E / 40$. This is within a factor of 4 theoretical tensile strength [33].

Once fractured, the ends of the particles are unbonded with the matrix and the stress transfer from the inclusion to the matrix is expected to be very different from the non-broken particles. We shall adopt a simple view where the stress follows a triangular evolution from zero at both ends and reaching its maximum in the middle of the precipitates as depicted on Fig. 7.

With this view the stress increases linearly with the following rate [34]:

$$
\frac{\mathrm{d} \sigma}{\mathrm{d} x}=\frac{2 \tau}{r}=\frac{\sigma_{f}}{r}
$$




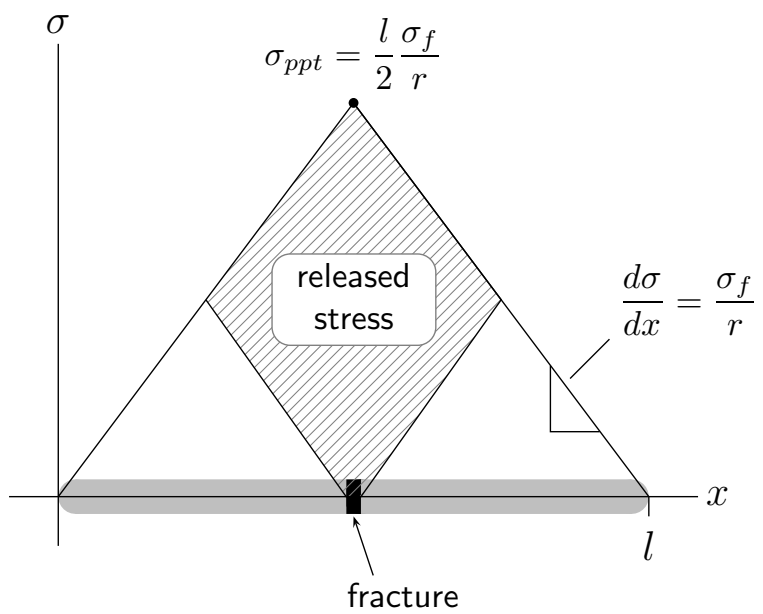

Figure 7. Stress distribution in the simple shear lag model and illustration of the break up when the load reaches the tensile strength of the precipitate; $x$ denotes the position along the precipitate length.

$\tau$ being the shear stress at the interface $\left(2 \tau=\sigma_{f}\right)$. Finally the average stress in the fibre is simply half the maximum stress:

$$
\overline{\sigma_{p p t}}=\frac{\sigma_{p p t}}{2}=\frac{l}{4} \frac{\sigma_{f}}{r}
$$

According to this model, the breakup of precipitates will lower the maximum stress (and thus the average stress) and the internal stress calculated by Eq. (10) will decrease. The internal stress drop is highlighted by the hatched area on Fig. 7 .

Of course, the fracture process is much more complex than the simple view we are developping here. First of all, the dislocation loops around the precipitates may not be perfectly equispaced, such that fracture may not occur at the centre of the precipitate. In addition, a precipitate will not be perfectly aligned with the $\langle 001\rangle$ direction of the $\mathrm{Al}$ matrix and its geometrical parameter be different from the average ones. To account for all these discrepancies, we have chosen to use a non unique fracture stress. A Gaussian distribution is used, centered on the mean value $\sigma_{u}$ and with a standard deviation $\widetilde{\sigma_{u}}$.

A consequence of using a Gaussian distribution for the fracture stress is the possibility to resolve readily the fraction of broken precipitates, which will be given exactly by the Gaussian cumulative distribution function. This is due to the fact that for a given stress $\sigma=E \varepsilon_{p}^{*}$ all the precipitates with $\sigma_{u} \leq \sigma$ will be broken. The total fraction of broken precipitates $p_{1}$ (the fraction of unbroken precipitates being $1-p_{1}$ ), 
can be obtained by:

$$
p_{1}=\frac{1}{2}\left(1+\operatorname{erf}\left(\frac{E \varepsilon_{p}^{*}-\sigma_{u}}{\widetilde{\sigma_{u}} \sqrt{2}}\right)\right)
$$

where $\operatorname{erf}$ is the Gauss error function: $\operatorname{erf}(x)=2 / \sqrt{\pi} \int_{0}^{x} \exp -t^{2} d t$. After the first fracture, the fraction of precipitates broken $i$ times $(i>1)$ among the ones broken $i-1$ times $^{1}$, is:

$$
p_{i}=\frac{1}{2}\left(1+\operatorname{erf}\left(\frac{\frac{\sigma_{f}}{r} \frac{l_{0}}{4 i}-\sigma_{u}}{\widetilde{\sigma_{u}} \sqrt{2}}\right)\right)
$$

5.2.3 Integration of the models. In order to fully describe the evolution of the internal stress carried out by the precipitates over a wide range of strain, we need to combine the models. The full model is constituted by a small computer program implementing the unrelaxed plastic strain expression stated by Eq. (9), the plastic shear lag model with the particle fracture. For completeness, the parameters used in the model have all been gathered in Table 8. Although all parameters have a physical meaning, some of them, namely $n^{*}$ and $\widetilde{\sigma_{u}}$ are not precisely known and the values have been chosen to fit the experimental data. $n^{*}$ controls the rate of the elastic build up of dislocation loops and the maximum stress reached in the precipitates. A value of $n^{*}=60$ was chosen to fit the data presented on Fig. 6. Although no precise measure is available in the literature to check this value, it is worth noting that preliminary TEM observations counting the number of dislocation loops around the precipitates (in dark field contrast) gave approximately 40 loops per precipitate after $8 \%$ tensile strain. Given the difficulty in making these measurements, we beleive this is in reasonable agreement with the maximum value of $n^{*}=60$. Now, with $\sigma_{u} \simeq E / 40$, the precipitate fracture occurs approximately for $\varepsilon_{p}^{*}=0.025$ which according to Fig. 6 will happend slightly before a strain of 0.1 . This is consistent with the experimental observations. In the end, a fracture stress variance of $170 \mathrm{MPa}$ is chosen to fit the internal stress drop measured experimentally.

The matrix flow stress evolution is taken from the experimental tensile behavior. Finally, combining

\footnotetext{
${ }^{1}$ In Eq. (15) the fraction $p_{i}$ is relative. For instance, since to break twice, a precipitate must first break once, the actual fraction of precipitate broken twice is $p_{1} p_{2}$.
} 
Table 8. Physical parameters used in the internal stress model.

\begin{tabular}{lcc}
\hline Parameter & Symbol & Value \\
\hline Volume fraction & $f$ & 0.019 \\
Young Modulus & $E$ & $118 \mathrm{GPa}$ \\
Orientation factor & $\alpha$ & 1 \\
Burger's vector & $b$ & $0.286 \mathrm{~nm}$ \\
Maximum number of loops & $n^{*}$ & 60 \\
Initial length & $l_{0}$ & $300 \mathrm{~nm}$ \\
Average radius & $r$ & $6.6 \mathrm{~nm}$ \\
Mean fracture stress & $\sigma_{u}$ & $2900 \mathrm{MPa}$ \\
Fracture stress standard dev. & $\widetilde{\sigma_{u}}$ & $170 \mathrm{MPa}$ \\
\hline
\end{tabular}

Eq. (14) and (15) the general form of the internal stress is given by:

$$
\langle\sigma\rangle=\underbrace{\left(1-p_{1}\right) f E \varepsilon_{p}^{*}}_{\text {unbroken precipitates }}+\underbrace{f p_{1}\left(1-p_{2}\right) \frac{l_{0}}{4} \frac{\sigma_{f}}{r}}_{\text {broken once }}+\underbrace{f p_{1} p_{2} \frac{l_{0}}{8} \frac{\sigma_{f}}{r}}_{\text {broken twice }}+\cdots
$$

The output of the simulation has been plotted in Fig. 8. One can see a very good agreement between the prediction by the model and the experimental values of internal stress measured by the Bauschinger tests. Fig. 8 shows that the initial internal stress carried out by the precipitates almost linearly increases with strain (initially $\varepsilon_{p}^{*}=\varepsilon$ ). This is followed by a regime where plastic relaxation occurs and then the precipitates start to fracture at a strain just below 0.1 resulting in a rapid drop of the internal stress. Due to increasing flow stress of the alloy $\sigma_{f}$ as the straining continues, most of the precipitates will fracture once more, further decreasing the stress borne by the precipitates. It is worth noting that with the current values of the parameters, a small fraction of the precipitates never fracture. Physically, this can be interpreted that some of the precipitates are oriented such that the load transfer is ineffective.

We are here standing at the limit of the continuum/discrete description of the deformation. The results of Fig. 8 show that adopting a physically based model taking into account the discrete nature of the dislocation/precipitates interaction is capable of describing micro-mechanical phenomena such as the internal stress build up and decrease, without having to explicitly account for the discrete view of the dislocation motion. However there could be a value for a discrete dislocation simulation to push further the physical description of those mechanisms by adopting a multiscale modeling framework. For example, discrete dislocation simulation could help to shape fundamental equations such as the rate of dislocation loop formation and provide physical input for the fitting parameters such as the fracture stress variance. 

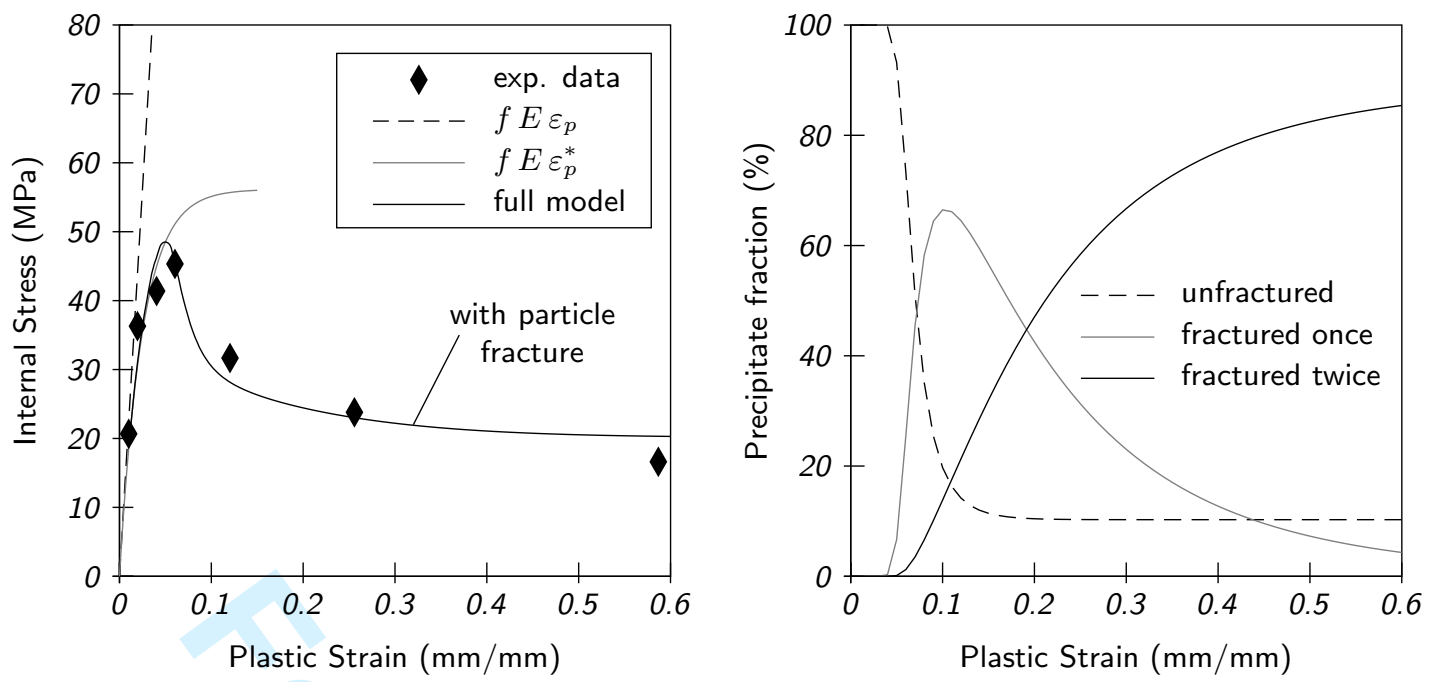

Figure 8. Results of the internal stress model: a) internal stress predicted by the model, as a comparison, the calculation for $f E \varepsilon$ and $f E \varepsilon_{p}^{*}$ have also been plotted b) evolution of the fraction of broken precipitates.

Yet, some points remain unclear at the moment. One is that with $\alpha=1$, the internal stress contributed from the precipitates has the form of $f E \varepsilon_{p}^{*}$; this implicitly supposes that all precipitates fully participate in the process. While this may be true in the case of spherical inclusion (such as the copper silica system), it is not true in our case since the precipitates are distributed with different orientations in the material with respect to the loading direction. There are several explanations possible to this issue. First one can argue that during deformation, the fibre-like precipitates tend to align with the loading direction. This will tend to lower down the orientation effect. Second, there are some uncertainties in the microstructural parameters values used in the model. Specifically, the Young modulus of the precipitates was evaluated from first principles and as such there may be some uncertainty in its value. Third, as previously discussed there is also a degree of uncertainty from the offset chosen to evaluate the internal stress from the Bauschinger tests. A direct measurement of the stress in the precipitates using for example, X-ray diffraction would be valuable.

\section{Conclusions}

The plastic deformation of a commercial precipitation strengthening aluminium alloy (AA6111) has been investigated for a large range of ageing conditions. The main results can be summarized as follows.

The development of internal stresses critically depends on the precipitates size and volume fraction. It 
has been shown that for the case of shearable particles, the development of long range internal stress is rather small and the work hardening is dominated by dislocation-dislocation interactions. On the other hand, for non-shearable precipitates, a significant fraction of the work hardening can be attributed to the development of internal stress. This is interpreted by long range elastic stresses produced by dislocation loops stored around the particles, and can be characterized by tension-compression test. It was found that plastic relaxation occurs after approximately $2 \%$ plastic strain. At higher strains, the dislocation loop storage is such that axial loading of the precipitates reaches a new regime where the precipitates fracture, reducing the internal stress in the material.

Following Brown and coworkers, the framework for modelling deformation in two phase materials has been revisited with the insight from the current experiments. First, a physically based expression for the unrelaxed plastic strain has been derived. This expression has been shown to accurately predict the plastic relaxation measured from Bauschinger experiments. To fully describe the internal stress evolution with the ongoing strain, a composite view of the material has been adopted. Within this view, a simple shear lag model has been used to compute the internal stress of the broken precipitates, allowing a good prediction of the internal stress development, up to strains of 0.6. This is, to the best of the authors knowledge, the first time that this regime is clearly identified and successfully modelled.

\section{Acknowledgement}

The authors greatfully acknowledge the help of C. Wolverton and Y. Wang for providing the elastic constants of the $Q$ phase via first principle calculations. The authors are thankful to Pr. C. W. Sinclair for helpful discussion and comments on the present work. H. P. would like to thank the French ministry of foreign affairs for the Lavoisier fellowship during his work at the University of British Columbia.

\section{References}

[1] J. D. Eshelby. The determination of the elastic field of an ellipsoidal inclusion, and related problems. Proceedings of the Royal Society of London, 241(1226):376-396, August 1957. 
[2] T.W. Clyne and P.J Withers. An Introduction To Metal Matrix Composites. Cambridge Solid State cience Series. Cambridge University Press, Cambridge, 1993.

[3] M. F. Ashby. Strengthening Methods in Crystals. John Wiley and Sons, New York, 1971.

[4] H. H. M. Cleveringa, E. Van Der Giessen, and A. Needleman. Comparison of discrete dislocation and continuum plasticity predictions for a composite material. Acta Materialia, 45(8):3163-3179, August 1997.

[5] J. D. Embury. Plastic flow in dispersion hardened materials. Metall. Trans. A, 16(12):2191, 1985.

[6] L. M. Brown and W. M. Stobbs. The work-hardening of copper-silica I. A model based on internal stresses, with no plastic relaxation. Philosophical Magazine, 23(185):1185-1199, 1971.

[7] L. M. Brown and W. M. Stobbs. The work-hardening of copper-silica II. The role of plastic relaxation. Philosophical Magazine, 23(185):1201-1233, 1971.

[8] N. A. Fleck, G. M. Muller, M. F. Ashby, and J. W. Hutchinson. Strain gradient plasticity: Theory and experiment. Acta Metallurgica et Materialia, 42(2):475-487, February 1994.

[9] C. M. Sargent and G. R. Purdy. Dissolution of small precipitates. Scripta Metallurgica, 8:569-572, 1974.

[10] I. Gutierrez-Urrutia, M.A. Munoz-Morris, and D.G. Morris. The effect of coarse second-phase particles and fine precipitates on microstructure refinement and mechanical properties of severely deformed al alloy. Materials Science and Engineering A, 394(12):399-410, March 2005.

[11] A. Deschamps, F. Bley, F. Livet, D. Fabregue, and L. David. In-situ small-angle X-ray scattering study of dynamic precipitation in an Al-Zn-Mg-Cu alloy. Philosophical Magazine, 83(6):677-692, February 2003.

[12] A. Kelly and R. B. Nicholson. Guinier preston zones in an aluminium-silver alloy. Acta Metallurgica, 12(2):277, February 1964.

[13] S. Tao and J. Embury. The mechanical behavior of directionally solidified Al-Ni in compression. Metallurgical and Materials Transactions A, 24(3):713-719, March 1993.

[14] J. G. Byrne, M. E. Fine, and A. Kelly. Precipitate hardening in an aluminum-copper alloy. Philosophical Magazine, 6:1119-1145, 1961.

[15] G. D. Moan and J. D. Embury. A study of the Bauschinger effect in aluminum-copper alloys. Acta Metallurgica, 27(5):903-914, May 1979.

[16] J.D. Atkinson, L. M. Brown, and W. M. Stobbs. The work-hardening of copper-silica IV. The Bauschinger effect and plastic relaxation. Philosophical Magazine, 30:1247-1280, 1974.

[17] L. M. Brown and D. R. Clarke. The work hardening of fibrous composites with particular reference to the copper-tungsten system. Acta Metallurgica, 25(3):563-570, May 1977.

[18] D. V. Wilson. Reversible work hardening in alloys of cubic metals. Acta Metallurgica, 13(7):807-814, July 1965.

[19] L. M. Brown. Orowan's explanation of the Bauschinger effect. Scripta Metallurgica, 11:127-131, 1977.

[20] X. Wang, W. J. Poole, S. Esmaeili, D. J. Lloyd, and J. D. Embury. Precipitation strengthening of the aluminum alloy AA6111. Metallurgical and Materials Transactions A: Physical Metallurgy and Materials Science, 34(12):2913-2924, December 2003.

[21] S. Esmaeili, X. Wang, D.J. Lloyd, and W.J. Poole. On the precipitation-hardening behavior of the Al-Mg-Si-Cu alloy AA6111. Metallurgical and Materials Transactions A, 34:751-763, 2003.

[22] X. Wang, S. Esmaeili, and D. J. Lloyd. The sequence of precipitation in the Al-Mg-Si-Cu alloy AA6111. Metallurgical and Materials Transactions A, 37(9):2691-2699, 2006.

[23] L.M. Cheng, W.J. Poole, J.D. Embury, and D.J. Lloyd. The influence of precipitation on the work hardening behavior of the 
aluminum alloys AA6111 and AA7030. Metallurgical and Materials Transactions A, 34:2913-2924, 2003.

[24] W. J. Poole, X. Wang, D. J. Lloyd, and J. D. Embury. The shearable/non-shearable transition in Al-Mg-Si-Cu precipitation hardening alloys: Implications on the distribution of slip, work hardening and fracture. Phil Mag., 85(26-27):3113-3135, September 2005.

[25] W. J. Poole and D. J. Lloyd. Modelling the stress-strain behaviour for aluminum alloy AA6111. In J. F. Nie, A. J. Morton, and B. C. Muddle, editors, Proceedings of the 9th International Conference on Aluminium Alloys, pages 939-945, Brisbane, 2004. Institute of Materials Engineering Australasia Ltd.

[26] R. E. Stoltz and R. M. Pelloux. Cyclic deformation and Bauschinger effect in Al-Cu-Mg alloys. Scripta Metallurgica, 8:269-276, 1974.

[27] R. J. Asaro. Elastic-plastic memory and kinematic-type hardening. Acta Metallurgica, 23:1255-1265, October 1975.

[28] D. J. Lloyd. The Bauschinger effect in polycrystalline aluminium containing coarse particles. Acta Metallurgica, 25(4):459-466, 1977.

[29] O. B. Pendersen, L. M. Brown, and W. M. Stobbs. The Bauschinger effect in copper. Acta Metallurgica, 29:1843-1850, 1981.

[30] C. W. Sinclair, W. J. Poole, and Y. Bréchet. A model for the grain size dependent work hardening of copper. Scripta Materialia, 55(8):739-742, August 2006.

[31] C. Wolverton. Crystal structure and stability of complex precipitate phases in $\mathrm{Al}-\mathrm{Cu}-\mathrm{Mg}-(\mathrm{Si})$ and $\mathrm{Al}-\mathrm{Zn}-\mathrm{Mg}$ alloys. Acta Materialia, 49:3129-3142, 2001.

[32] W. F. Hosford. The Mechanics Of Crystals And Textured Polycrystals. Oxford University Press, 1993.

[33] A. Kelly and N.H. Macmillan. Strong Solids. Clarendon press, Oxford, 3rd edition edition, 1986.

[34] H. Lilholt. Hardening in two phase materials - II. plastic strain and mean stress hardening rate. Acta Metallurgica, 25:587-593, 1977. 
(a)

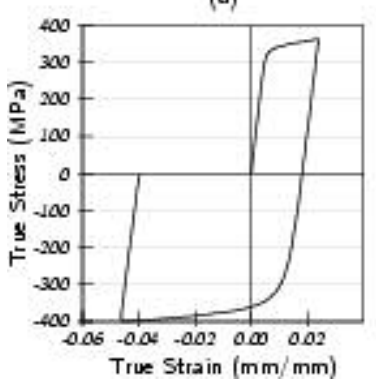

(b)

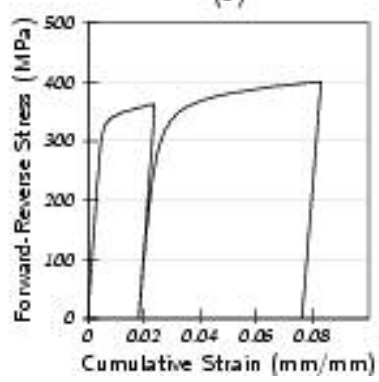

(c)

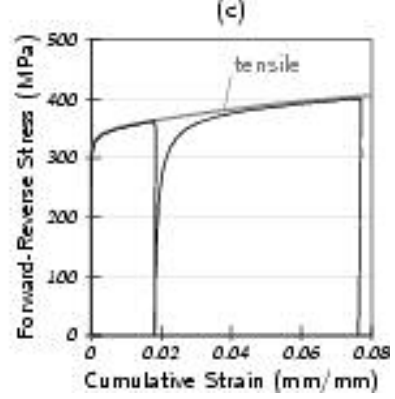

Illustration of the stress-strain data processing in a three steps way in the case of $7 \mathrm{H} 180$ material with $2 \%$ forward strain: (a) true stress v.s. true strain curve; (b) reversed stress data plotted v.s. cumulative true strain (c) the elastic strain is removed and the curve is compared with the monotonic behavior.

$158 \times 53 \mathrm{~mm}(72 \times 72 \mathrm{DPI})$ 

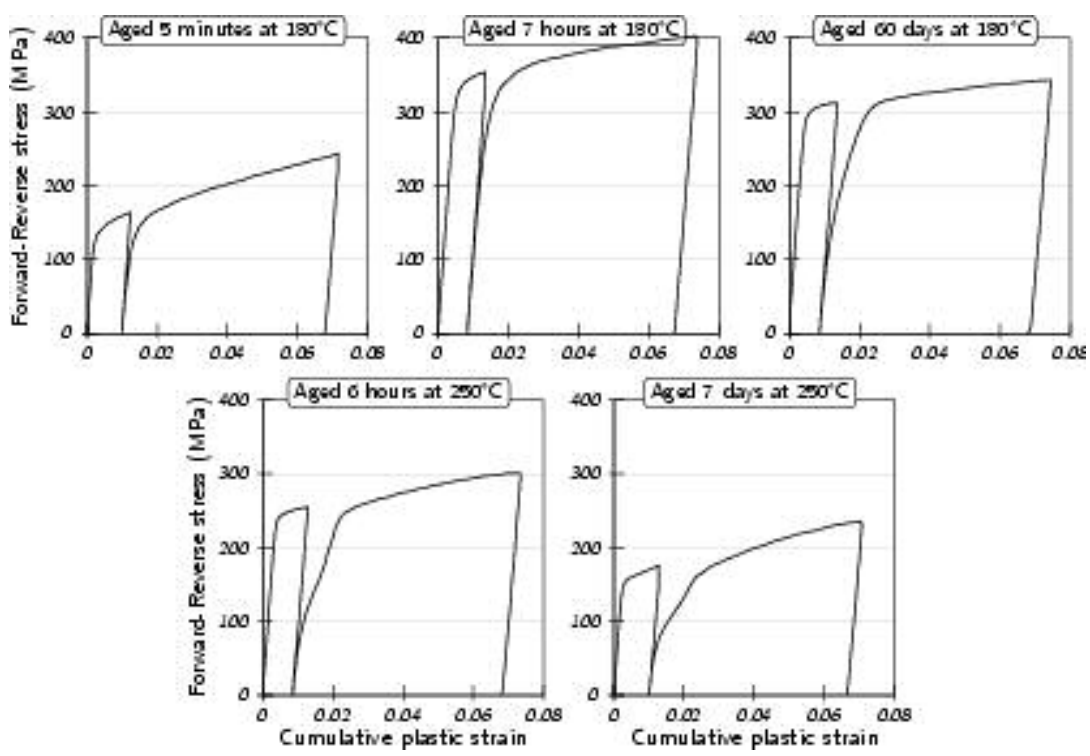

Forward-reverse stress/strain curves, obtained by a Bauschinger test with a 1\% forward plastic strain, for all materials.

$145 \times 99 \mathrm{~mm}$ (72 x 72 DPI) 

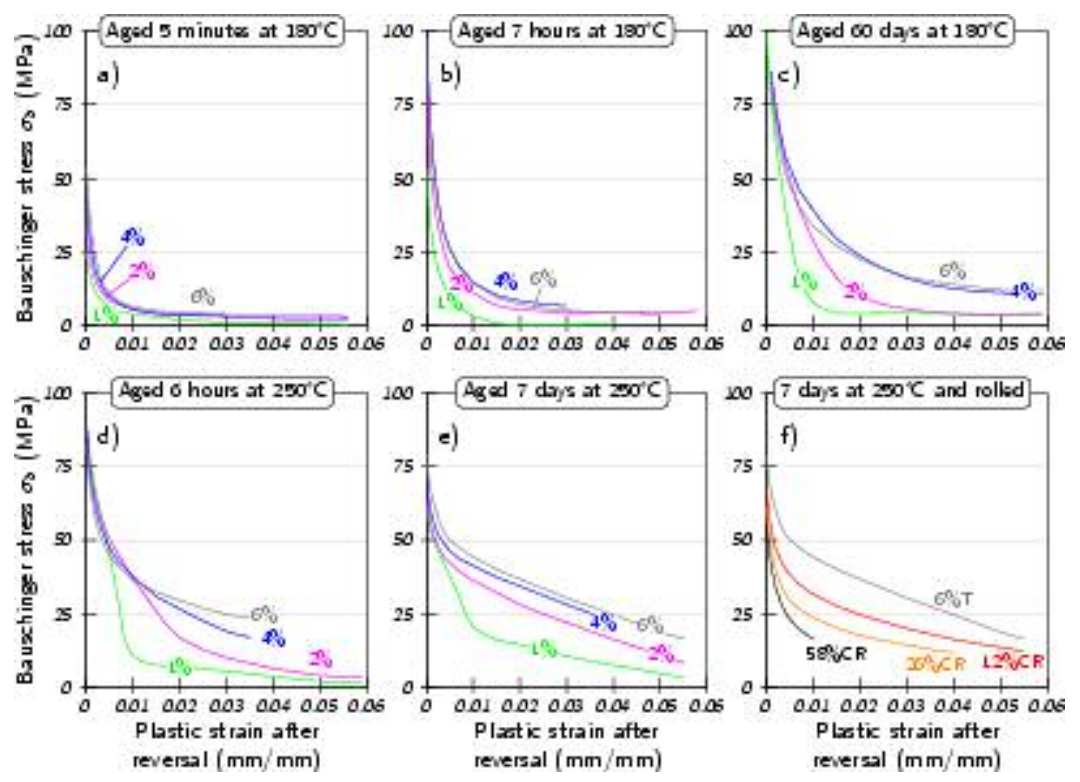

Bauschinger stress as a function of reverse plastic strain. For each ageing condition, 4 different forward strains were tested $(1 \%, 2 \%, 4 \%$ and $6 \%)$; the curves for rolled samples are shown in the bottom right graph and have been annoted "CR". $142 \times 102 \mathrm{~mm}(72 \times 72$ DPI $)$ 

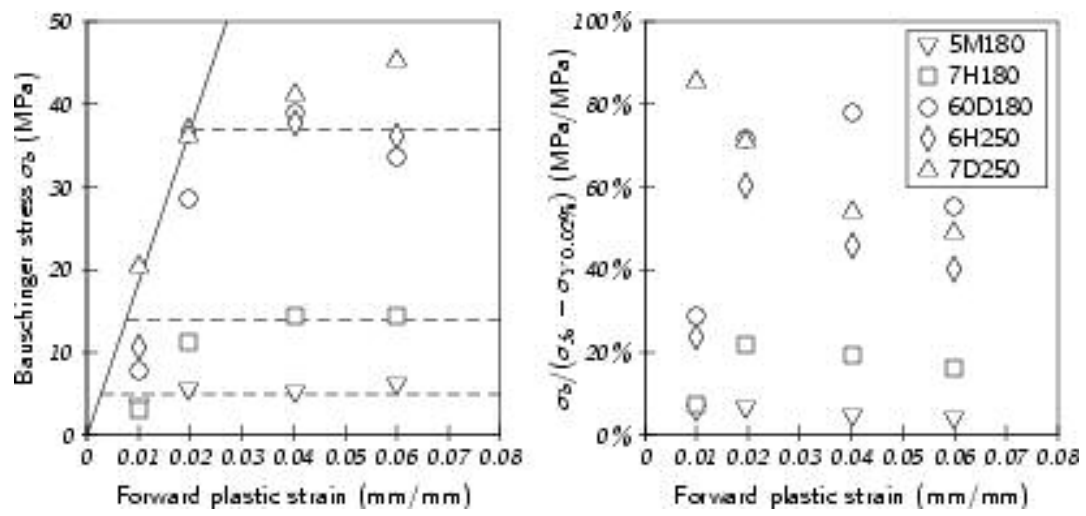

Internal stress measurements in AA6111, a) $<\sigma>$ measured after $1 \backslash \%$ reverse strain, b) $<\sigma>$ expressed as a percentage of the work hardening of the materials; symbols denote the same materials in both pictures.

$144 \times 67 \mathrm{~mm}(72 \times 72 \mathrm{DPI})$ 
(a)

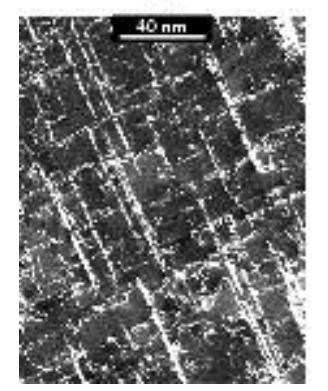

(b)

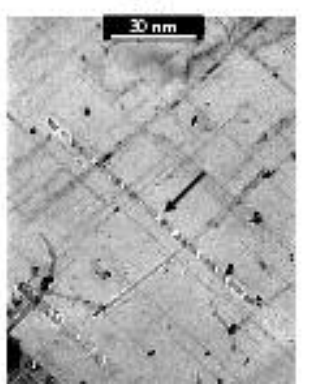

(c)

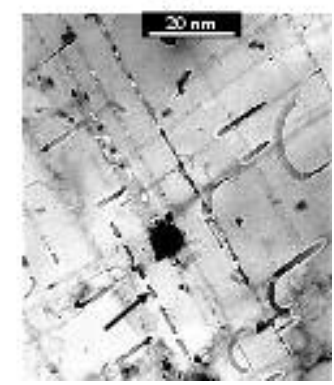

Observation of the microstructure of material 7D250 by TEM: a) dark field image of a sample deformed $8 \%$ in tension, b) bright field image after $20 \%$ cold rolling, c) bright field image after $40 \%$ cold rolling; arrows indicate examples of precipitates fracture. $130 \times 56 \mathrm{~mm}(72 \times 72 \mathrm{DPI})$ 


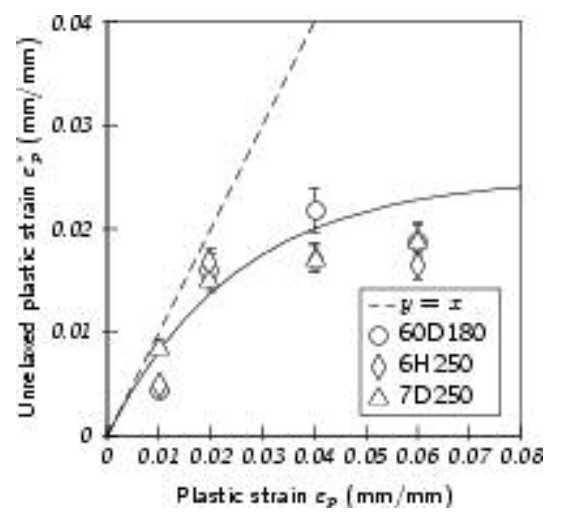

Prediction of the unrelaxed plastic strain by Eq. (9) with $n *=60$ compared to the values issued from the experiments and calculated with Eq. (3); as before, the error bars are based on a $200 \mathrm{MPa}$ uncertainty in the measure of $\boldsymbol{\theta}$.

$71 \times 66 \mathrm{~mm}(72 \times 72 \mathrm{DPI})$ 


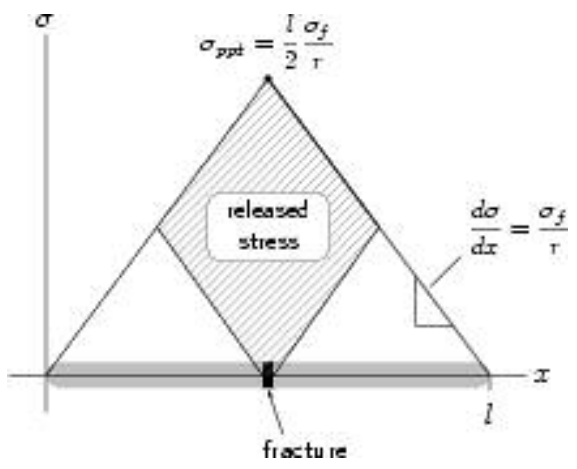

Stress distribution in the simple shear lag model and illustration of the break up when the load reaches the tensile strength of the precipitate; $x$ denotes the position along the precipitate length.

$75 \times 59 \mathrm{~mm}(72 \times 72$ DPI $)$ 

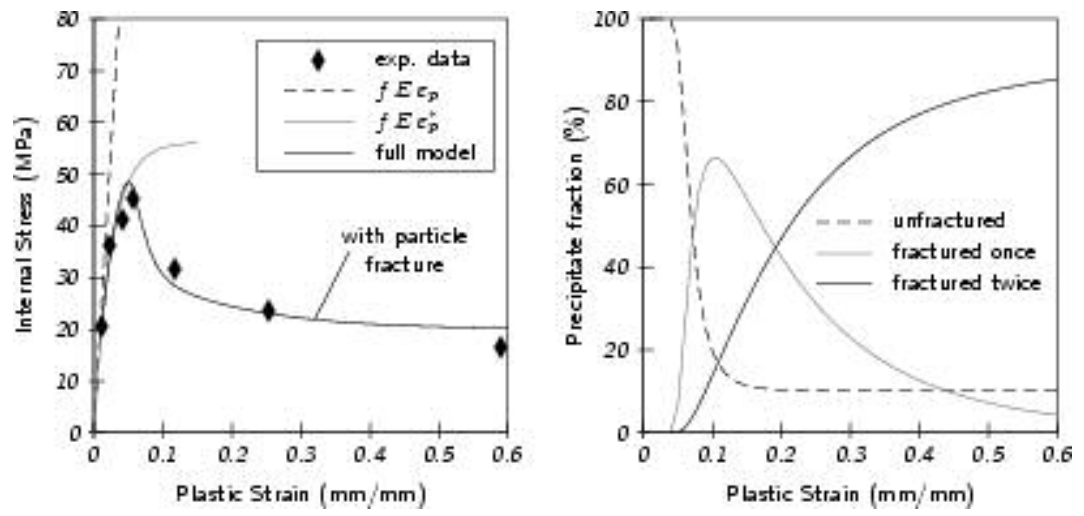

Results of the internal stress model: a) internal stress predicted by the model, as a comparison, the calculation for $\mathrm{fE} \varepsilon$ and $\mathrm{fE} \varepsilon * \mathrm{p}$ have also been plotted $\mathrm{b}$ ) evolution of the fraction of broken precipitates. $143 \times 67 \mathrm{~mm}(72 \times 72 \mathrm{DPI})$ 